\title{
CAMA
}

Centre for Applied Macroeconomic Analysis

\section{Mortality and Urbanization: An African Tragedy}

\section{CAMA Working Paper 66/2016 October 2016}

\section{Markus Brueckner}

Research School of Economics, ANU and

Centre for Applied Macroeconomic Analysis, ANU

\section{Abstract}

Since the 1980s, no significant negative relationship exists in sub-Saharan Africa between adult mortality and urbanization. In the rest of the world, the relationship between adult mortality and urbanization is significantly negative. High prevalence of HIV likely explains the absence of a significant negative relationship between adult mortality and urbanization in sub-Saharan Africa. HIV can spread more rapidly in the city than in the countryside because the costs of finding multiple sexual partners are lower in the city than in the countryside. During the 1960s and 1970s, i.e. prior to the HIV pandemic, adult mortality and urbanization are significantly negatively correlated in sub-Saharan Africa. 


\section{Keywords}

\section{JEL Classification}

\section{Address for correspondence:}

(E) cama.admin@anu.edu.au

\section{ISSN 2206-0332}

The Centre for Applied Macroeconomic Analysis in the Crawford School of Public Policy has been established to build strong links between professional macroeconomists. It provides a forum for quality macroeconomic research and discussion of policy issues between academia, government and the private sector.

The Crawford School of Public Policy is the Australian National University's public policy school, serving and influencing Australia, Asia and the Pacific through advanced policy research, graduate and executive education, and policy impact. 


\title{
Mortality and Urbanization: An African Tragedy
}

\author{
September 2016
}

Markus Brueckner

Australian National University

\begin{abstract}
Since the 1980s, no significant negative relationship exists in sub-Saharan Africa between adult mortality and urbanization. In the rest of the world, the relationship between adult mortality and urbanization is significantly negative. High prevalence of HIV likely explains the absence of a significant negative relationship between adult mortality and urbanization in sub-Saharan Africa. HIV can spread more rapidly in the city than in the countryside because the costs of finding multiple sexual partners are lower in the city than in the countryside. During the 1960s and 1970s, i.e. prior to the HIV pandemic, adult mortality and urbanization are significantly negatively correlated in sub-Saharan Africa.
\end{abstract}

\footnotetext{
Markus Brueckner is Professor in the Research School of Economics, Australian National University; he is also an affiliate of CAMA. Address: LF Crisp Building 26A, Australian National University, Canberra, ACT 0200, Australia. Email: markus.brueckner@anu.edu.au. For constructive feedback on a previous version of the paper the author is grateful to Alison Booth, Tim Hatton, Hal Hill, Matthew Gray, and Rabee Tourky; comments received at the Silvaplana workshop in political economy, in particular, from my discussants Carsten Hefeker and Niklas Potrafke, are greatly appreciated.
} 


\section{Introduction}

According to data provided by the World Bank (2015) sub-Saharan Africa is the region with the highest adult mortality. The average mortality rate of a person between ages 15 and 60 living in subSaharan Africa in the year 2010 was around 0.3. In the rest of the world the adult mortality rate in 2010 was around 0.1 . Over the past five decades adult mortality has declined in the sub-Saharan African region but at a rate that is smaller than for the rest of the world. In 1960 the adult mortality rate in sub-Saharan Africa was around 0.4; in the rest of the world that figure was around 0.3. Noteworthy is that in sub-Saharan Africa adult mortality increased in the mid-1980s and 1990s; and it decreased in the mid-2000s. For the rest of the world no such discontinuity in the decline in adult mortality is visible. See Figure 1.

The share of the sub-Saharan African population that lives in urban areas is low by international comparison and the rate of change during the past five decades is not substantially different to the rest of the world. This is shown in Figure 2. The average urbanization rate in the sub-Saharan African region was around 20 percentage points in the 1960s. Over the past five decades the rate has increased by around 20 percentage points. Today around 40 percent of the subSaharan African population lives in urban areas. This is around 20 percentage points lower than in the rest of the world.

The above observations suggest a difference in the mortality-urbanization relationship between sub-Saharan Africa and the rest of the world. The paper further examines the relationship between mortality and urbanization using a panel model. One advantage of the panel model is that it allows to control for unobservable time-invariant country characteristics and common non-linear time trends. Another advantage of the model is that it allows to examine how the relationship between mortality and urbanization is affected by country-specific characteristics, in particular, the incidence of disease.

Based on a sample of 190 countries during 1960-2013, estimates of a panel model show a 
significant difference in the relationship between adult mortality and urbanization between subSaharan Africa and the rest of the world. In sub-Saharan Africa during 1960-2013 the average relationship between adult mortality and urbanization is not significantly negative. During that time period there is a significant negative relationship between adult mortality and urbanization for the rest of the world.

The model estimates show that during 1960-2013, for the sample of countries in the world that excludes sub-Saharan Africa, a 10 percentage point increase in the urbanization rate was associated with a decrease in the adult mortality rate of around 2 percentage points on average. This is a quantitatively sizable and statistically significant relationship. For sub-Saharan Africa the model estimates show that during 1960-2013 the average relationship between adult mortality and urbanization is statistically indistinguishable from zero and quantitatively small. ${ }^{1}$

Sub-Saharan Africa is plagued by a high incidence of infectious diseases, such as malaria and HIV. The paper explores how the relationship between adult mortality and urbanization is affected by cross-country differences in the incidence of such diseases. It is important to note that the transmission mechanism of HIV is different from malaria: Malaria is transmitted to humans by Anopheles mosquitos while HIV is transmitted via bodily fluids of an HIV-infected person, i.e. from person to person.

Consider how the costs of prevention of the spread of diseases differ between urban and rural areas. For mosquito-borne diseases, the most direct way to prevent the spread of these diseases is by large-scale fumigation of mosquitos. The average costs (per person) of fumigating mosquitos is lower in cities than in the countryside. This suggests that it is cheaper on a per capita basis to prevent the spread of mosquito-born diseases in urban areas than in rural areas. ${ }^{2}$

For HIV another, countervailing force is relevant: the cost of finding multiple sexual

1 1960-2013 is the longest possible time period given the availability of data from the World Bank (2015).

2 Donnelly et al. (2005) note that malaria has been considered a predominantly rural disease in Africa. The authors reference studies that show Anopheles mosquito breeding decreases with increasing proximity to the centre of urban areas. 
partners is lower in cities than in the countryside. Micro data show that urban residence in subSaharan African countries significantly increases the likelihood that an individual engages in multiple sexual partnerships (Uchidi et al., 2012; Berhan and Berhan, 2015). There is no evidence that behavior of unprotected sex (i.e. sex without the use of condoms) is systematically less frequent in urban areas of sub-Saharan African countries. Noteworthy is that, historically, the HIV epidemic emerged first in urban areas and then spread to rural areas of sub-Saharan African countries (Andoh et al., 2006). During the 2000s the prevalence of HIV in urban areas of sub-Saharan African countries was about 50 percent higher than in rural areas (Hajizadeh et al., 2014). According to the World Health Organization (2012), AIDS is the disease that during the 2000s caused more deaths in sub-Saharan Africa than any other disease: over 10 percent of deaths in sub-Saharan Africa were caused by AIDS during the 2000s.

Panel model estimates show that HIV prevalence significantly affects the relationship between adult mortality and urbanization: HIV prevalence significantly weakens the negative relationship between adult mortality and urbanization, so much so, that for values of HIV prevalence equal to the average of the sub-Saharan African region the relationship between adult mortality and urbanization is insignificant. The panel model estimates show that under the hypothetical case of HIV prevalence rates being equal in sub-Saharan Africa to the world average, adult mortality and urbanization would have been significantly negatively related in the subSaharan African region.

It is noteworthy that the panel model estimates show no significant difference in the relationship between infant mortality and urbanization between sub-Saharan Africa and the rest of the world. In sub-Saharan Africa, urbanization is on average significantly negatively associated with infant mortality during 1960-2013 (but not with adult mortality). ${ }^{3}$ The model estimates show that HIV significantly weakens the negative correlation between urbanization and infant mortality but

3 The paper's finding that infant mortality and urbanization are significantly negatively correlated in sub-Saharan Africa is in line with Fink et al. (2017) who document that in low and middle income countries infant mortality is significantly lower in cities than in rural areas. 
the effect is smaller than for adult mortality. An explanation for this result is that HIV can be transmitted from a HIV-positive mother to her child, however, transmission rates, while positive, are below unity. According to UNAIDS (1999) the mother-to-child HIV transmission rate is around $25 \%-35 \%$ in the absence of any intervention; when breastfeeding is strictly avoided the transmission rate is around $10 \%$.

The panel model enables to explore how the relationship between adult mortality and urbanization differs over time. The HIV pandemic occurred in the post-1980 period. Splitting the sample into pre-1980 and post-1980, the panel model estimates show that for the 1960s and 1970s, the relationship between adult mortality and urbanization is significantly negative in sub-Saharan Africa. For the post-1980 period it is positive and statistically indistinguishable from zero. I.e., it is the post-1980 period that is driving the overall insignificant average relationship between adult mortality and urbanization for sub-Saharan Africa during 1960-2013.

The high incidence of mosquito-born diseases, such a malaria, yellow fever, and dengue, in sub-Saharan Africa cannot explain why in that region there is no systematic relationship between adult mortality and urbanization during 1960-2013. The panel model estimates show that a high incidence of mosquito-born diseases strengthens the negative relationship between adult mortality and urbanization. A high incidence of mosquito-born diseases therefore cannot explain why in subSaharan Africa there is no systematic relationship between adult mortality and urbanization during the past five decades.

An important question is to what extent (the absence of) a significant correlation between adult mortality and urbanization reflects (the absence of) a causal effect of the latter variable on the former? The paper documents that the above results hold when controlling for GDP per capita. This suggests that the above findings are not simply a result of differences in countries' incomes. It is difficult to establish causality at the country level: the main contribution of the paper is to present some interesting correlations between adult mortality and urbanization and provide an explanation 
for why these correlations differ for sub-Saharan Africa and the rest of the world.

The rest of the paper is organized as follows. Section 2 introduces the econometric model. Section 3 discusses results from the estimation of the model. Section 4 concludes.

\section{Econometric Model}

The following three econometric models will be used as a baseline for the empirical analysis:

(1) Mortality $_{\mathrm{ct}}=\mathrm{a}_{1 \mathrm{c}}+\mathrm{b}_{1 \mathrm{t}}+\theta_{1} \mathrm{Urban}_{\mathrm{ct}}+\mathrm{e}_{\mathrm{lct}}$

(2) Mortality $_{\mathrm{ct}}=\mathrm{a}_{2 \mathrm{c}}+\mathrm{b}_{2 \mathrm{t}}+\theta_{2} \mathrm{Urban}_{\mathrm{ct}}+\theta_{3} \mathrm{Urban}_{\mathrm{ct}} * \mathrm{SSA}_{\mathrm{c}}+\mathrm{e}_{2 \mathrm{ct}}$

(3) Mortality $_{\mathrm{ct}}=\mathrm{a}_{3 \mathrm{c}}+\mathrm{b}_{3 \mathrm{t}}+\theta_{4} \mathrm{Urban}_{\mathrm{ct}}+\theta_{5} \mathrm{Urban}_{\mathrm{ct}} * \operatorname{SSA}_{\mathrm{c}}+\theta_{6} \operatorname{Urban}_{\mathrm{ct}} *\left(\mathrm{X}_{\mathrm{c}}-\mathrm{X}\right)+\mathrm{e}_{3 \mathrm{ct}}$

where $a_{c}$ are country fixed effects; $b_{t}$ are year fixed effects; $S S A$ is an indicator variable that is unity if a country is part of the sub-Saharan African region. The error term, $e_{c t}$, may be arbitrarily serially correlated for each country; the computed standard errors of the estimated coefficients account for this type of heteroscedasticity by being Huber robust and clustered at the country level. For a list of the countries in the sample see Appendix Table 1. Appendix Table 2 provides a definition of the variables. Appendix Table 3 lists the variables' means.

In equation (1) the coefficient $\theta_{1}$ measures the average relationship between mortality and urbanization for all countries in the sample. In equation (2) the coefficient $\theta_{1}$ measures the average relationship between mortality and urbanization for the rest of the world, i.e. all countries excluding sub-Saharan Africa. The coefficient $\theta_{2}$ measures the difference in the mortality-urbanization relationship between sub-Saharan Africa and the rest of the world. The mortality-urbanization relationship for sub-Saharan Africa is $\theta_{1}+\theta_{2}$. Equation (3) enables to examine how the relationship between mortality and urbanization depends on country-specific (average) characteristics, $\mathrm{X}_{\mathrm{c}}$. $\mathrm{X}$ is the average of $\mathrm{X}_{\mathrm{c}}$ in the sample of 190 countries. Note that $\mathrm{X}_{\mathrm{c}}$ does not show up independently in equation (3). The reason is that the model includes country fixed effects, $\alpha_{c}$. $X_{c}$ is a country average, i.e. the variable does not vary across time. The reason why the country average is used for $\mathrm{X}$ is 
because time-series data on HIV and mosquito-borne disease are very sparse.

Differentiating equation (3) with respect to Urban one obtains:

$$
\rho=\theta_{4}+\theta_{5} * \mathrm{SSA}_{\mathrm{c}}+\theta_{6}\left(\mathrm{X}_{\mathrm{c}}-\mathrm{X}\right)
$$

where $\rho \equiv d\left(\right.$ Mortality $\left._{c t}\right) / d\left(\operatorname{Urban}_{c t}\right)$. From equation (4) one sees that the coefficient $\theta_{6}$ measures how the relationship between mortality and urbanization differs depending on the country-specific characteristic, $X_{c}$.

The interpretation of $\theta_{4}$ and $\theta_{5}$ in equation (3) is different from the interpretation of the $\theta^{\prime}$ s in equation (2). The coefficient $\theta_{4}$ is a measure of the relationship between mortality and urbanization for the rest of the world, under the hypothetical case that the average country-characteristic $\mathrm{X}_{\mathrm{c}}$ in that region is identical to the world average $X$. The coefficient $\theta_{5}$ measures the difference in the mortality-urbanization relationship between sub-Saharan Africa and the rest of the world, under the hypothetical case that the average country-characteristic $X_{c}$ in sub-Saharan Africa is identical to the world average $\mathrm{X}$.

\section{Results}

Column (1) of Table 1 presents estimates of the average relationship between adult mortality and urbanization for a sample of 190 countries during 1960-2013. From column (1) we see that the estimated coefficient on Urbanization is -0.13 ; the standard error is 0.06 . One can reject the hypothesis that this coefficient is equal to zero at the 5 percent significance levels (p-value 0.03 ). Quantitatively, the coefficient in column (1) can be interpreted as a 10 percentage points increase in urbanization being associated, on average, with a 1 percentage points decrease in the adult mortality rate for a world sample of 190 countries during 1960-2013.

Column (2) shows that there exists a significant difference in the relationship between urbanization and adult mortality for sub-Saharan Africa and the rest of the world. The coefficient on Urbanization*SSA is 0.22 and significantly different from zero at the conventional significance 
levels. The coefficient on Urbanization is -0.17 and also significantly different from zero at the conventional significance levels. The sum of coefficients on Urbanization and Urbanization*SSA is 0.05. The $\mathrm{p}$-value from a test that this sum is equal to zero is 0.67 . This implies that, at the conventional significance levels, one cannot reject the hypothesis that urbanization and adult mortality are unrelated in sub-Saharan Africa during 1960-2013.

Column (3) shows that HIV significantly mediates the relationship between urbanization and adult mortality. The coefficient on Urbanization ${ }^{*} H I V$ is 0.05 and has a standard error of 0.01 . Figure 3 facilitates interpretation by plotting on the y-axis the sum of coefficients on Urbanization and Urbanization*HIV; on the x-axis are the values of countries' average prevalence of HIV. The figure shows that the relationship between adult mortality and urbanization is a positive function of HIV prevalence. Only in countries in which HIV prevalence is low, i.e. no greater than 3 percent, is there a significant negative relationship between adult mortality and urbanization. The relationship between adult mortality and urbanization is statistically indistinguishable from zero for intermediate values of HIV prevalence. For high values of HIV prevalence, i.e. above 10 percent, adult mortality and urbanization are significantly positively related.

Column (3) of Table 1 shows that conditional on Urbanization*HIV the coefficient on Urbanization*SSA is negative and significantly different from zero at the conventional significance levels. Adding up the coefficients on Urbanization*SSA and Urbanization yields a sum that is negative, around -0.25 . One can reject that this sum is equal to zero at the 1 percent significance level. The interpretation of this result is that were HIV prevalence in sub-Saharan Africa equal to the world average then urbanization and adult mortality would be significantly negatively correlated.

Table 2 shows that the above findings are robust to controlling for GDP per capita. One can see that the coefficient on GDP per capita is negative; i.e. countries with higher national income have on average lower adult mortality rates. ${ }^{4}$ One can also see that in Table 2 the estimated

4 This is in line with previous literature that has found a significant negative relationship between mortality and GDP 
coefficients on Urbanization are quantitatively and statistically similar to Table 1.

Table 3 shows results for infant mortality. From column (1) one can see that the average relationship between infant mortality and urbanization is negative. Quantitatively, the estimated coefficient suggests that a ten percentage points increase in the urbanization rate is associated with a decrease in the infant mortality rate of around 1 percentage point. Column (2) shows that the coefficient on Urbanization*SSA is 0.03 and has a standard error of 0.03 . At the conventional significance levels, one cannot reject the hypothesis that the relationship between infant mortality and urbanization is the same in sub-Saharan Africa and the rest of the world. The coefficient on Urbanization*SSA in column (2) of Table 3 is about one-seventh the size of the coefficient on Urbanization*SSA in column (2) of Table 1. In column (2) of Table 3 the sum of coefficients on Urbanization and Urbanization*SSA is 0.07 . One can reject the hypothesis that this sum of coefficients is equal to zero at the 1 percent significance level (p-value 0.007).

The estimates of column (2) in Table 3 suggest that urbanization and infant mortality are significantly negatively correlated, in sub-Saharan Africa and in the rest of the world. In line with that result, column (3) of Table 3 shows that the coefficient on $H I V^{*}$ Urbanization is quantitatively small, 0.004. The coefficient on Urbanization*HIV in column (2) of Table 3 is about one-tenth the size of the coefficient on Urbanization*HIV in column (2) of Table 1. As noted in the introduction, the risk of an HIV infected mother transmitting HIV to an infant is around $25 \%-35 \%$ absent intervention; without breastfeeding the transmission risk is around $10 \%$.

Table 4 reports results for life expectancy. Column (1) shows that, on average, urbanization and life expectancy were positively correlated during 1960-2013. The coefficient in column (1) on Urbanization is 0.13 and has a standard error of 0.04 . One can reject the hypothesis that this coefficient is equal to zero at the 1 percent significance level. The interpretation of the coefficient in column (1) of Table 4 is that a 10 percentage point increase in the urbanization rate is associated with an increase in life expectancy of 1 year.

per capita (see e.g. Pritchett and Summers, 1996; Brueckner and Schwandt, 2015). 
Table 5 presents estimates of the relationship between urbanization and adult mortality for sub-Saharan Africa: column (1) shows estimates for the 1960-2013 period; and in columns (2) and (3) the sample is split into pre and post-1980, respectively. From column (1) one can see that during 1960-2013 the average relationship in sub-Saharan Africa between adult mortality and urbanization is quantitatively small and statistically insignificant. Column (2) shows that during the 1960s and 1970s, i.e. before the HIV pandemic, there was a significant negative relationship between adult mortality and urbanization in sub-Saharan Africa. The coefficient on Urbanization is around -0.24 and has a standard error of 0.06 . For the post-1980 period the coefficient on Urbanization is 0.06 , and one cannot reject the hypothesis that this coefficient is equal to zero at the conventional significance levels. These findings are in line with the hypothesis that HIV is an important mediating factor in the relationship between adult mortality and urbanization.

Figure 4 plots the coefficients on Urbanization, for the sample of sub-Saharan African countries, for each of the five decades during 1960-2010. One can see that in the 1960s and 1970s the coefficients are negative and quantitatively sizable. From the 1980s to the 1990s the coefficients on Urbanization increase and become positive in sign: at peak, in the 1990s, the coefficient on Urbanization is around 0.1 . In the 2000 s the coefficient on Urbanization is around 0 . That is, there is a decline in the coefficient on Urbanization from the 1990s to the 2000s. A possible explanation for this is that administering antiretorvial drugs and spreading information of how to prevent HIV is cheaper per capita in the city than in the countryside; and there were implementation lags in the development of drugs and education policies, e.g. effective antiretorviral drugs became available only towards the end of the 1990s.

Table 6 reports estimates of how the relationship between adult mortality and urbanization is affected by the incidence of mosquito-born disease. The three mosquito-born diseases considered are malaria (column (1)), yellow fever (column (2)), and dengue fever (column (3)). One can see that the coefficient on the interaction term Urbanization and mosquito-born disease is negative for 
all three diseases considered: the presence of mosquito-born diseases makes it more likely that urbanization is associated with lower adult mortality. This implies that a high incidence of mosquito-born diseases in sub-Saharan Africa cannot explain why in that region there was no significant average relationship between adult mortality and urbanization during the past five decades. Indeed, Table 6 shows that the coefficient on Urbanization*SSA remains positive and significantly different from zero in model specifications that include interaction terms between Urbanization and mosquito-born diseases.

\section{Conclusion}

Data from the World Bank (2015) show that during the past five decades there exists no systematic negative relationship between adult mortality and urbanization in sub-Saharan Africa. The absence of a systematic negative relationship between adult mortality and urbanization in the sub-Saharan African region is surprising. The paper explored whether the absence of a significant negative relationship between adult mortality and urbanization in the sub-Saharan African region can be explained the high incidence of HIV in that region. Panel model estimates showed that under the hypothetical case of HIV incidence being equal in sub-Saharan Africa to the world average, adult mortality and urbanization would have been significantly negatively correlated in the sub-Saharan African region. The absence of a significant negative relationship between urbanization and adult mortality in sub-Saharan Africa for the post-1980 period is an African tragedy that is likely due to the high incidence of HIV in that region.

A potentially fruitful avenue of future work could be to examine how institutions affect the relationship between urbanization and mortality. Justesen (2012) finds that access to treatment of HIV/AIDS is more readily available in democracies than autocracies. Rowley (2000) points to a political culture of kleptocracy as the reason for dismal economic performance of sub-Saharan African countries. D'Agostino et al. (2016) argue that the negative effects of corruption are 
compounded by high military burdens in sub-Saharan African countries. The above papers suggest that sub-Saharan African countries are characterized by institutions that distinguishes the region from other continents; following the spirit of these papers future work may examine how institutions affect the relationship between urbanization and mortality. 


\section{References}

Andoh, S., M. Umezak, K. Nakamura, M. Kizuki, and T. Takano (2006). "Correlation between national income, HIV/AIDS and political status and mortalities in African countries." Public Health 120: 624-633.

Berhan, Y., and A. Berhan (2015). "A Meta Analysis of Risky Sexual Behaviour among Male Youth in Developing Countries." AIDS Research and Treatment. Article ID 580961

Brueckner, M. (2012). "Economic Growth, Size of the Agricultural Sector, and Urbanization in Africa." Journal of Urban Economics 71: 26-36.

Brueckner, M. and H. Schwandt (2015). "Income and Population Growth." Economic Journal 125: 1653-1676.

D'Agostino, G., J. Dunne, and L. Pieroni (2016). "Corruption and Growth in Africa." European Journal of Political Economy 43: 71-88.

Donnelly, M., P. McCall, C. Lengeler, I. Bates, U. D'Alessandro, G. Barnish, F. Konradsen, E. Klinkenberg, H. Townson, J.-F. Trape, I. Hastings, and C. Mutero (2005). "Malaria and urbanization in sub-Saharan Africa." Malaria Journal 4-12.

Feenstra, R., R. Inklaar, and M. Timmer (2013). "The Next Generation of the Penn World Table." Online Database. Available for download at www.ggdc.net/pwt.

Fink, G., I. Guenther, and K. Hill (2017). Urban Mortality Transitions: The Role of Slums. In "New Approaches to Death in Cities during the Health Transition", Ramiro Fariñas, Diego, Oris, Michel (Eds.), Springer, 2017.

Gallup, J., J. Sachs, and A. Mellinger (1999). "Geographic and Economic Development." International Regional Science Review 22: 179-232.

Hajizadeh, M., S. Drissa, J. Heymann, and A. Nandi (2014). "Socioeconomic inequalities in HIV/AIDS prevalence in sub-Saharan African countries: evidence from the Demographic Health Surveys." International Journal for Equity in Health 13-18.

Institute of Medicine (2010). Infectious disease movement in a borderless world. Washington, DC: The National Academies Press.

Justesen, M. (2012). "Democracy, Dictatorship, and Disease: Political Regimes and HIV/AIDS." European Journal of Political Economy 28: 373-389.

Pritchett, L. and L. Summers (1996). "Wealthier is Healthier." Journal of Human Resources 31: 841-868.

Uchudi, J., M. Magadi, and M. Mostazir (2012). "A multilevel analysis of the determinants of highrisk sexual behaviour in sub-Saharan Africa." Journal of Biosocial Science 44: 289-311.

UNAIDS (1999). "Prevention of HIV transmission from mother to child." Available for download at http://www.unaids.org/sites/default/files/media_asset/prevention_en_0.pdf 
UNAIDS (2010). Global Report Facts Sheet.

Rowley, C. (2000). "Political Culture and Economic Performance in Sub-Saharan Africa." European Journal of Political Economy 16: 133-158.

World Health Organization (2012). "Causes of Death". Online Database. Available for download at: http://www.who.int/healthinfo/global_burden_disease/estimates/en/index1.html

World Bank (2015). "World Development Indicators." Online Database. Available for download at http://data.worldbank.org/data-catalog/world-development-indicators 
Figure 1. Adult Mortality

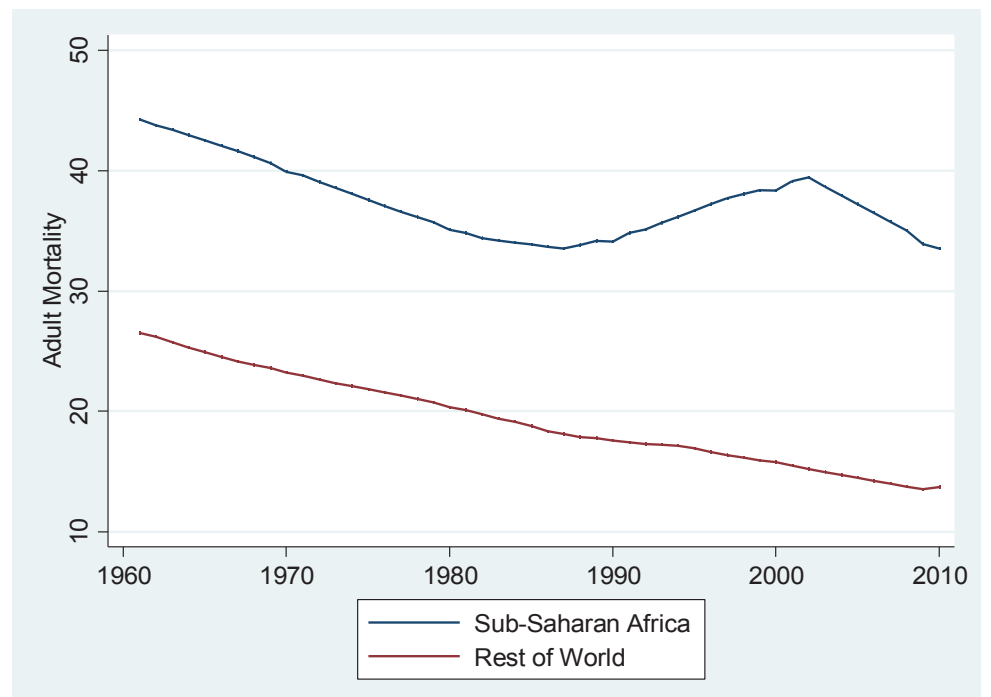

Note: For a definition of "Adult Mortality" see Appendix Table 2. "Rest of World" refers to the sample of 190 countries that excludes sub-Saharan African countries. See Appendix Table 1 for the list of countries in the sample. 
Figure 2. Urbanization

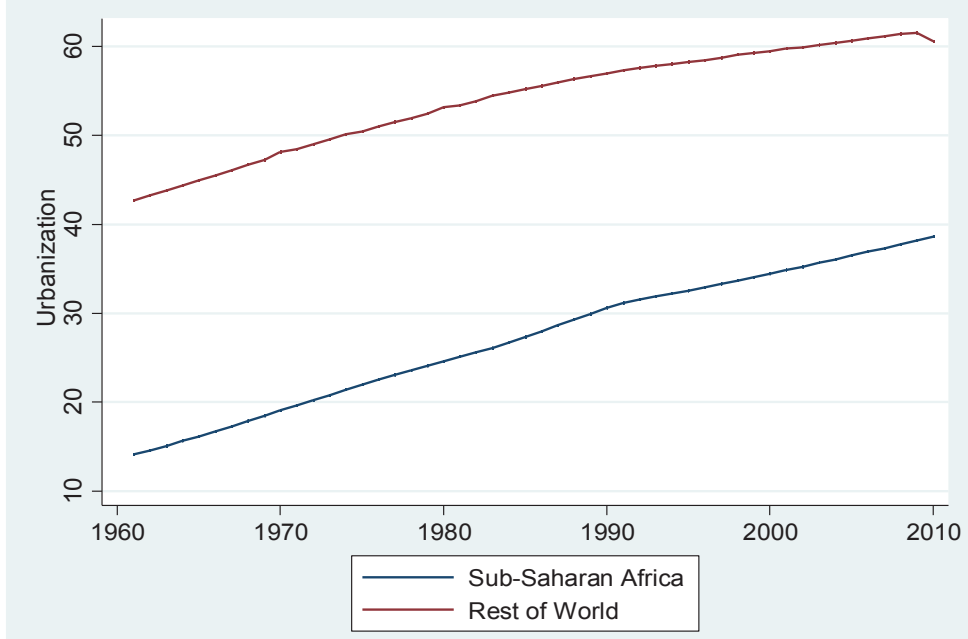

Note: For a definition of "Urbanization" see Appendix Table 2. "Rest of World" refers to the sample of 190 countries that excludes subSaharan African countries. See Appendix Table 1 for the list of countries in the sample. 
Figure 3. Adult Mortality and Urbanization: The Role of HIV

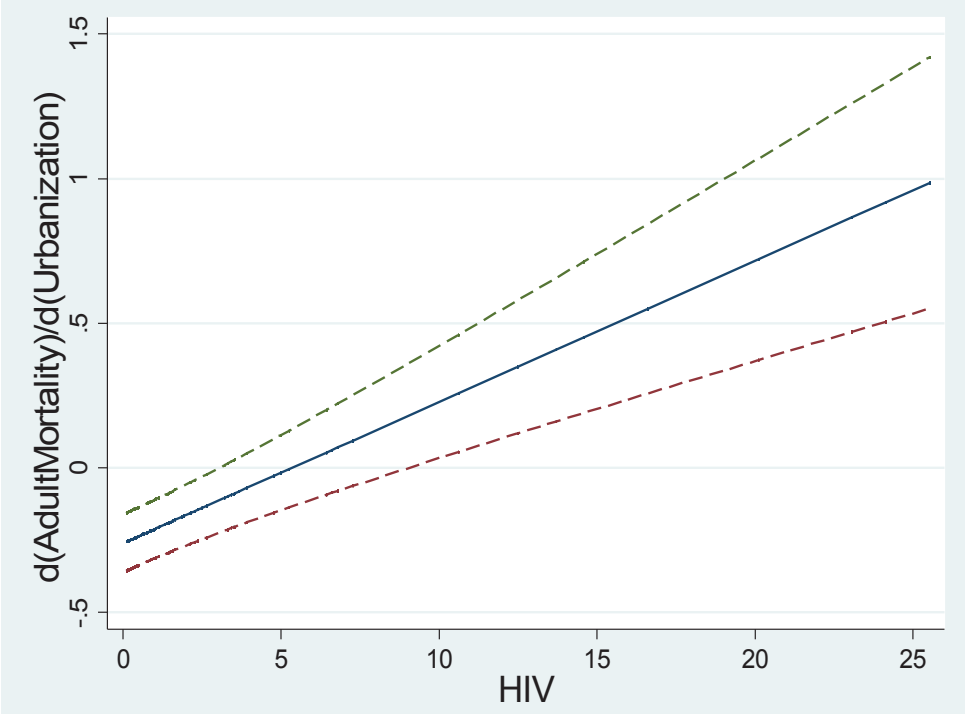

Note: The figure is based on the following estimating equation: AdultMortality $_{c t}=a_{c}+b_{t}+\pi_{l}$ Urbanization $_{c t}+\pi_{2}$ Urbanization $_{c t} * H I V_{c}$ $+u_{c t .}$. The solid line is the sum of the estimated coefficients $\pi_{1}+\pi_{2} * \mathrm{HIV}_{\mathrm{c}}$. The dashed lines are the $95 \%$ confidence bands. 
Figure 4. Adult Mortality and Urbanization in Sub-Saharan Africa

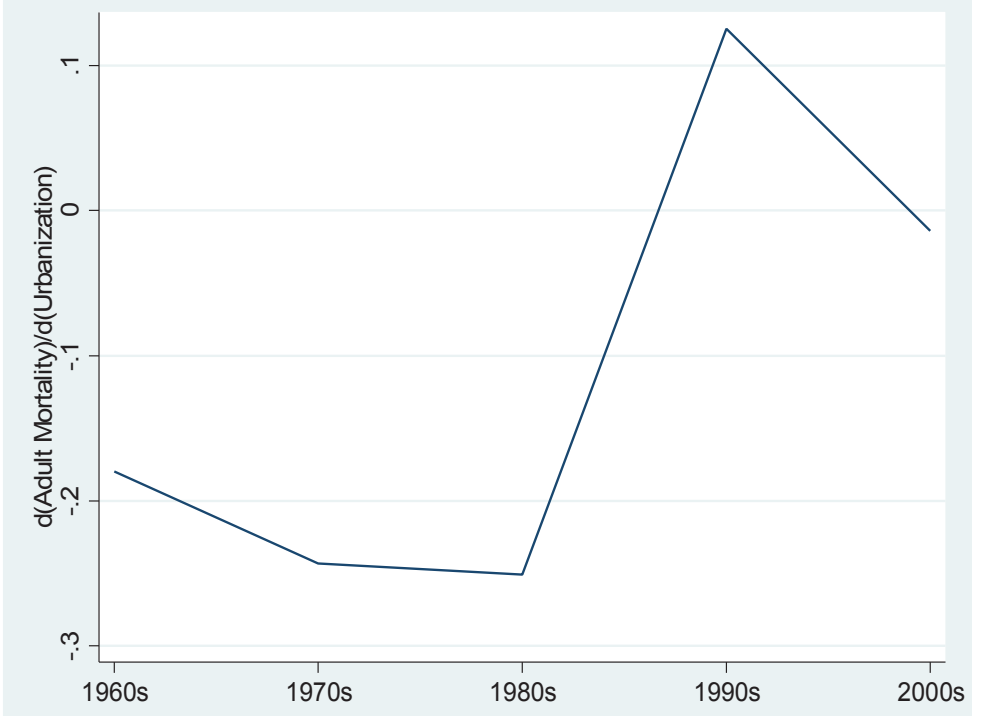

Note: The figure is based on the following estimating equation: AdultMortality $_{c t}=a_{c}+b_{t}+\chi$ Urbanization $_{c t}+u_{c t}$. The equation is estimated for sub-Saharan African countries for five sub-periods: the 1960s (1960-1969); the 1970s (1970-1979); the 1980s (1980-1989); the 1990s (1990-1999); and the 2000s (2000-2009). The figure shows a line plot of the estimated coefficients $\chi$ for these sub-periods. 
Table 1. Adult Mortality and Urbanization

\begin{tabular}{lccc}
\hline & \multicolumn{3}{c}{ Adult Mortality } \\
\hline & $(1)$ & $(2)$ & $(3)$ \\
& LS & LS & LS \\
Urbanization & -0.13 & -0.17 & -0.13 \\
& $(0.06)$ & $(0.05)$ & $(0.06)$ \\
Urbanization * SSA & & 0.22 & -0.12 \\
& & $(0.11)$ & $(0.07)$ \\
Urbanization * HIV & & 0.05 \\
& & & $(0.01)$ \\
Country FE & Yes & Yes & Yes \\
Year FE & Yes & Yes & Yes \\
Observations & 9651 & 9651 & 7467 \\
Countries & 190 & 190 & 144 \\
\hline
\end{tabular}

Note: The method of estimation is least squares. Standard errors (shown in parentheses) are Huber robust and clustered at the country level. "SSA" is a dummy variable that is unity for sub-Saharan African countries. 
Table 2. Adult Mortality, Urbanization, and GDP per capita

\begin{tabular}{lccc}
\hline & & & \\
& Adult Mortality & $(3)$ \\
& LS & LS & LS \\
Urbanization & -0.14 & -0.23 & -0.15 \\
& $(0.07)$ & $(0.05)$ & $(0.05)$ \\
Ln GDP per capita & -1.43 & -1.73 & -3.21 \\
& $(1.00)$ & $(0.79)$ & $(0.78)$ \\
Urbanization * SSA & & 0.20 & -0.18 \\
& & $(0.10)$ & $(0.06)$ \\
Ln GDP per capita * SSA & & 3.93 & $(1.01$ \\
Urbanization * HIV & & $(2.29)$ & 0.06 \\
Country FE & & & $(0.01)$ \\
Year FE & Yes & Yes & Yes \\
Observations & Yes & Yes & Yes \\
Countries & 7111 & 7111 & 6146
\end{tabular}

Note: The method of estimation is least squares. Standard errors (shown in parentheses) are Huber robust and clustered at the country level. "SSA" is a dummy variable that is unity for sub-Saharan African countries. 
Table 3. Infant Mortality and Urbanization

\begin{tabular}{lccc}
\hline & \multicolumn{3}{c}{ Infant Mortality } \\
\hline & $(1)$ & $(2)$ & $(3)$ \\
& LS & LS & LS \\
Urbanization & -0.09 & -0.10 & -0.07 \\
& $(0.02)$ & $(0.03)$ & $(0.03)$ \\
Urbanization * SSA & & 0.03 & -0.02 \\
& & $(0.03)$ & $(0.03)$ \\
Urbanization * HIV & & & 0.004 \\
Country FE & Yes & Yes & $(0.001)$ \\
Year FE & Yes & Yes & Yes \\
Observations & 8277 & 8277 & Yes \\
Countries & 180 & 180 & 6869 \\
\hline
\end{tabular}

Note: The method of estimation is least squares. Standard errors (shown in parentheses) are Huber robust and clustered at the country level. "SSA" is a dummy variable that is unity for sub-Saharan African countries. 
Table 4. Life Expectancy and Urbanization

Life Expectancy

LS

LS

Urbanization

0.13

0.18

0.15

(0.04)

(0.04)

(0.04)

Urbanization * SSA

$-0.12$

0.03

(0.06)

(0.05)

Urbanization * HIV

(0.01)

$\begin{array}{lccc}\text { Country FE } & \text { Yes } & \text { Yes } & \text { Yes } \\ \text { Year FE } & \text { Yes } & \text { Yes } & \text { Yes } \\ \text { Observations } & 9643 & 9643 & 7467 \\ \text { Countries } & 188 & 188 & 144\end{array}$

Note: The method of estimation is least squares. Standard errors (shown in parentheses) are Huber robust and clustered at the country level. "SSA" is a dummy variable that is unity for sub-Saharan African countries. 
Table 5. Adult Mortality and Urbanization in sub-Saharan Africa

\begin{tabular}{lccc}
\hline \multicolumn{3}{c}{ Adult Mortality } & \\
\hline & $(1)$ & $(2)$ & $(3)$ \\
& LS & LS & LS \\
& $1960-2013$ & Pre-1980 1980 \\
Urbanization & -0.06 & -0.24 & 0.06 \\
Country FE & $(0.22)$ & $(0.06)$ & $(0.31)$ \\
Year FE & Yes & Yes & Yes \\
Observations & Yes & Yes & Yes \\
Countries & 2390 & 856 & 1534 \\
\hline
\end{tabular}

Note: The method of estimation is least squares. Standard errors (shown in parentheses) are Huber robust and clustered at the country level. 
Table 6. Adult Mortality and Urbanization: The Role of Mosquito-Borne Diseases

\begin{tabular}{|c|c|c|c|}
\hline \multicolumn{4}{|c|}{ Adult Mortality } \\
\hline & (1) & (2) & (3) \\
\hline & $\mathrm{LS}$ & LS & LS \\
\hline Urbanization & $\begin{array}{l}-0.29 \\
(0.07)\end{array}$ & $\begin{array}{l}-0.26 \\
(0.06)\end{array}$ & $\begin{array}{l}-0.21 \\
(0.06)\end{array}$ \\
\hline Urbanization * SSA & $\begin{array}{c}0.73 \\
(0.19)\end{array}$ & $\begin{array}{c}0.45 \\
(0.18)\end{array}$ & $\begin{array}{l}0.25 \\
(0.12)\end{array}$ \\
\hline Urbanization * Malaria & $\begin{array}{l}-0.68 \\
(0.19)\end{array}$ & & \\
\hline $\begin{array}{l}\text { Urbanization * Yellow } \\
\text { Fever }\end{array}$ & & $\begin{array}{l}-0.34 \\
(0.17)\end{array}$ & \\
\hline $\begin{array}{l}\text { Urbanization * Dengue } \\
\text { Fever }\end{array}$ & & & $\begin{array}{l}-0.08 \\
(0.07)\end{array}$ \\
\hline Country FE & Yes & Yes & Yes \\
\hline Year FE & Yes & Yes & Yes \\
\hline Observations & 8263 & 8104 & 8104 \\
\hline Countries & 160 & 157 & 157 \\
\hline
\end{tabular}

Note: The method of estimation is least squares. Standard errors (shown in parentheses) are Huber robust and clustered at the country level. 
Appendix Table 1. List of Countries

\begin{tabular}{|c|c|c|c|c|}
\hline Afghanistan & Comoros $\left(^{*}\right)$ & Hong Kong & Mauritius & Solomon Islands \\
\hline Albania & Congo, Rep. $\left(^{*}\right)$ & Hungary & Mexico & Somalia $\left(^{*}\right)$ \\
\hline Algeria & Costa Rica & Iceland & Micronesia & South Africa (*) \\
\hline Angola (*) & Croatia & India & Moldova & Spain \\
\hline Antigua and Barbuda & Cuba & Indonesia & Mongolia & Sri Lanka \\
\hline Argentina & Cyprus & Iran. & Morocco & St. Kitts and Nevis \\
\hline Armenia & Czech Republic & Iraq & Mozambique $\left(^{*}\right)$ & St. Lucia \\
\hline Aruba & Cote d'Ivoire $\left({ }^{*}\right)$ & Ireland & Myanmar & St. Vincent \& Grenadines \\
\hline Australia & Denmark & Israel & Namibia $\left({ }^{*}\right)$ & Sudan $\left({ }^{*}\right)$ \\
\hline Austria & Djibouti $\left(^{*}\right)$ & Italy & Nepal & Suriname \\
\hline Azerbaijan & Dominica & Jamaica & Netherlands & Swaziland $\left(^{*}\right)$ \\
\hline Bahamas, The & Dominican Republic & Japan & New Caledonia & Sweden \\
\hline Bahrain & Ecuador & Jordan & New Zealand & Switzerland \\
\hline Bangladesh & Egypt. & Kazakhstan & Nicaragua & Syrian Arab Republic \\
\hline Barbados & El Salvador & Kenya $\left(^{*}\right)$ & Niger $\left(^{*}\right)$ & Sao Tome \& Principe $\left(^{*}\right)$ \\
\hline Belarus & Equatorial Guinea $\left(^{*}\right)$ & Kiribati & Nigeria $\left({ }^{*}\right)$ & Tajikistan \\
\hline Belgium & Eritrea $\left(^{*}\right)$ & Korea, Dem. Rep. & Norway & Tanzania $\left({ }^{*}\right)$ \\
\hline Belize & Estonia & Korea, Rep. & Oman & Thailand \\
\hline $\operatorname{Benin}\left({ }^{*}\right)$ & Ethiopia $\left({ }^{*}\right)$ & Kuwait & Pakistan & Togo $\left(^{*}\right)$ \\
\hline Bhutan & Fiji & Kyrgyz Republic & Panama & Tonga \\
\hline Bolivia & Finland & Lao PDR & Papua New Guinea & Trinidad and Tobago \\
\hline Bosnia and Herzegovina & France & Latvia & Paraguay & Tunisia \\
\hline Botswana $\left({ }^{*}\right)$ & French Polynesia & Lebanon & Peru & Turkey \\
\hline Brazil & Gabon $\left(^{*}\right)$ & Lesotho $\left(^{*}\right)$ & Philippines & Turkmenistan \\
\hline Brunei Darussalam & Gambia $\left(^{*}\right)$ & Liberia $\left(^{*}{ }^{\prime}\right.$ & Poland & Uganda $\left(^{*}\right)$ \\
\hline Bulgaria & Georgia & Libya & Portugal & Ukraine \\
\hline Burkina Faso (*) & Germany & Lithuania & Puerto Rico & United Arab Emirates \\
\hline Burundi $\left({ }^{*}\right)$ & Ghana $\left({ }^{*}\right)$ & Luxembourg & Qatar & United Kingdom \\
\hline Cambodia & Greece & Macao & Russian Federation & United States \\
\hline Cameroon $\left({ }^{*}\right)$ & Greenland & Macedonia & Rwanda (*) & Uruguay \\
\hline Canada & Grenada & Madagascar $\left({ }^{*}\right)$ & Samoa & Uzbekistan \\
\hline Cabo Verde & Guam & Malawi $\left(^{*}\right)$ & Saudi Arabia & Vanuatu \\
\hline Central African Rep. $\left({ }^{*}\right)$ & Guatemala & Malaysia & Senegal $\left({ }^{*}\right)$ & Venezuela \\
\hline Chad $\left(^{*}\right)$ & Guinea $\left({ }^{*}\right)$ & Maldives & Seychelles $\left(^{*}\right)$ & Vietnam \\
\hline Channel Islands & Guinea-Bissau (*) & Mali $\left({ }^{*}\right)$ & Sierra Leone $\left({ }^{*}\right)$ & Virgin Islands \\
\hline Chile & Guyana & Malta & Singapore & Yemen \\
\hline China & Haiti & Marshall Islands & Slovak Republic & Zambia $\left({ }^{*}\right)$ \\
\hline Colombia & Honduras & Mauritania $\left(^{*}\right)$ & Slovenia & Zimbabwe $\left(^{*}\right)$ \\
\hline
\end{tabular}

Note: Sub-Saharan African countries are marked with a $\left({ }^{*}\right)$. 


\section{Appendix Table 2. Definition of Variables}

\begin{tabular}{|l|l|} 
Variable & \\
\hline Urbanization & $\begin{array}{l}\text { Percentage of a country's population living in urban areas as defined by national statistical offices. } \\
\text { Source: World Bank (2015) }\end{array}$ \\
\hline GDP per capita & Constant price PPP GDP per capita. Source: Feenstra et al. (2015) \\
\hline Adult Mortality & $\begin{array}{l}\text { The probability of dying between the ages of } 15 \text { and 60. The variable is measured in percentage } \\
\text { points. Source: World Bank (2015) }\end{array}$ \\
\hline Infant Mortality & $\begin{array}{l}\text { The probability that an infant dies before reaching one year of age. The variable is measured in } \\
\text { percentage points. Source: World Bank (2015) }\end{array}$ \\
\hline Life Expectancy & $\begin{array}{l}\text { The number of years a newborn infant in a country would live if prevailing patterns of mortality at } \\
\text { the time of its birth were to stay the same throughout its life. Source: World Bank (2015) }\end{array}$ \\
\hline HIV & Percentage of the population ages 15-49 who are infected with HIV. Source World Bank (2015) \\
\hline Malaria & Percentage of population living in areas with malaria. Source: Gallup et al. (1999) \\
\hline Yellow Fever & Percentage of population living in areas with yellow fever. Source: Gallup et al. (1999) \\
\hline Dengue & Percentage of population living in areas with dengue fever. Source: Gallup et al. (1999) \\
\hline
\end{tabular}


Appendix Table 3. Averages of Variables

\begin{tabular}{lcc}
\hline & Sub-Saharan Africa & Rest of World \\
Urbanization & 27 & 57 \\
GDP per capita & 2147 & 12286 \\
Adult Mortality & 37 & 18 \\
Infant Mortality & 10 & 4 \\
Life Expectancy & 50 & 68 \\
HIV & 6 & 0.5 \\
Malaria & 85 & 11 \\
Yellow Fever & 63 & 7 \\
Dengue Fever & 38 & 30 \\
\hline
\end{tabular}

